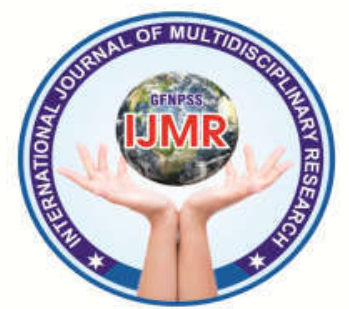

\title{
A CBCT STUDY OF EVALUATION OF LINGUAL FORAMEN IN DENTAL
} IMPLANTS PATIENTS

\author{
DR. BHAVNA BARTHUNIA ${ }^{1}$, DR. POULOMI BHAKTA ${ }^{2}$ \\ ${ }^{1}$ PROF. \& HOD, DEPT. OF ORAL MEDICINE \& RADIOLOGY, DASWANI DENTAL \\ COLLEGE \& RESEARCH CENTRE, RANPUR, KOTA, RAJASTHAN, INDIA \\ ${ }^{2}$ SENIOR LECTURER, DEPT. OF ORAL MEDICINE \& RADIOLOGY, DASWANI \\ DENTAL COLLEGE \& RESEARCH CENTRE,RANPUR, KOTA, RAJASTHAN, INDIA
}

Corresponding Email: poulomibhakta@gmail.com

\section{ABSTRACT}

Background: Lingual foramen needs careful assessment in mandibular anterior region. The present study was conducted to evaluate lingual foramen with CBCT.

Materials \& Methods: The present study was conducted on 52 partially edentulous patients of both genders. Only those patients who required dental implant in mandibular anterior region were selected. In all patients, CBCT scan was obtained with Densply sirona CBCT machine using field of view used of $5 \mathrm{X} 5 \mathrm{~cm}$. The length of the canal, distance from canal to buccal cortical plate, distance from canal to lingual cortical plate, distance from canal to inferior body of mandible, distance from canal to alveolus was calculated.

Results: There were equal number (26) of males and females. The length of the canal was $9.02 \pm 1.23 \mathrm{~mm}$ in males and $8.98 \pm 1.57 \mathrm{~mm}$ in females. Distance from canal to buccal cortical plate found to be $4.72 \pm 1.56 \mathrm{~mm}$ in males and $4.20 \pm 1.62 \mathrm{~mm}$ in females. Distance from canal to lingual cortical plate was $8.72 \pm 0.72 \mathrm{~mm}$ in group I and $8.26 \pm 1.04 \mathrm{~mm}$ in females. Distance from canal to inferior border was $8.74 \pm 2.41 \mathrm{~mm}$ in males and $7.76 \pm 2.32 \mathrm{~mm}$ in females. Distance from canal to alveolus found to be $11.68 \pm 3.36 \mathrm{~mm}$ in males and was $12.25 \pm 3.10$ $\mathrm{mm}$ in females. The difference was significant $(\mathrm{P}<0.05)$.

Conclusion: The length of the canal, distance from canal to buccal cortical plate, lingual cortical plate, to inferior border and to alveolus found to be more in males than females.

Key words: Buccal, CBCT, Lingual foramen 


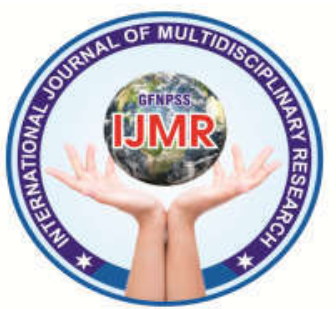

\section{INTRODUCTION:}

The lingual foramen, though an opening usually present in the midline on the lingual aspect of the anterior part of the mandible, could have variations in number and position. The branches of the sublingual artery-a branch of the lingual artery-and submental artery-a branch of facial artery-send branches to the peripheral muscles, mylohoid muscle, mucous membrane, and gingiva. ${ }^{1}$ The anastomosis of the two sublingual arteries has been suggested to be the blood supply of the chin. This single artery and its minor branches tend to exit the bone through structures that have been referred to in the literature as the anterior lingual foramina. Racial and ethnic variations in anatomical landmarks are not uncommon. There is little known about the incidence or location of the anterior lingual foramen. ${ }^{2}$ Dental implants procedures have increased over a period of time. The high demand of implants may be due to high survival rate. There is need of careful evaluation of implant site to prevent failure rates.

Clinical importance lies in the possibility of injuring the sublingual artery during trauma or in various surgical procedures. The artery is big enough to cause severe bleeding when injured during oral surgery.
This risk of haemorrage can lead to the obstruction of the upper airway because of the hematoma that forms in the floor of the mouth. CBCT provides useful information in deciding best implant site and assessment of lingual foramen. ${ }^{3}$ The present study was conducted to assess the position of lingual foramen using CBCT.

\section{MATERIALS \& METHODS}

The present study was conducted on 52 partially edentulous patients of both genders. All were informed regarding the study and written consent was obtained. Ethical clearance was obtained prior to the study. General information such as name, age, gender etc. was recorded. Only those patients who required dental implant in mandibular anterior region were selected. In all patients, CBCT scan was obtained with Densply sirona CBCT machine using field of view used of $5 \mathrm{X} 5 \mathrm{~cm}$. Exposure parameters such as $72 \mathrm{k} \mathrm{Vp}, 8 \mathrm{Ma}$ and exposure time of 18 seconds were used. All the planes such as axial, coronal and sagittal were constructed. The length of the canal, distance from canal to buccal cortical plate, distance from canal to lingual cortical plate, distance from canal to inferior body of mandible, distance from canal to alveolus in patients were calculated. Results thus obtained were 


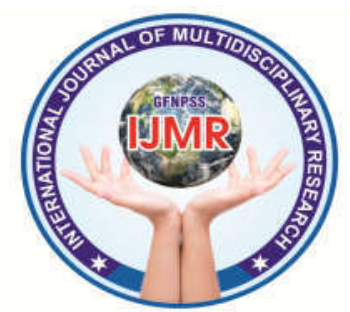

subjected to statistical analysis. $\mathrm{P}$ value $<$

\section{DISCUSSION}

0.05 was considered significant.

\section{RESULTS}

Table I shows that there were equal number (26) of males and females. Table II shows that the length of the canal was $9.02 \pm 1.23 \mathrm{~mm}$ in males and $8.98 \pm 1.57 \mathrm{~mm}$ in females. Distance from canal to buccal cortical plate found to be $4.72 \pm 1.56 \mathrm{~mm}$ in males and $4.20 \pm 1.62 \mathrm{~mm}$ in females. Distance from canal to lingual cortical plate was $8.72 \pm 0.72 \mathrm{~mm}$ in group I and $8.26 \pm 1.04 \mathrm{~mm}$ in females.Distance from canal to inferior border was $8.74 \pm 2.41 \mathrm{~mm}$ in males and $7.76 \pm 2.32 \mathrm{~mm}$ in females. Distance from canal to alveolus found to be $11.68 \pm 3.36 \mathrm{~mm}$ in males and was $12.25 \pm 3.10 \mathrm{~mm}$ in females. The difference was significant $(\mathrm{P}<0.05)$.

\begin{tabular}{|c|c|c|c|}
\hline \multicolumn{3}{|c|}{ Total- 52} & \\
\hline Gender & Iales & Females & \\
\hline Number & 26 & 26 & \\
\hline \multicolumn{4}{|c|}{ Table II: Measurements of lingual foramen } \\
\hline Parameters (mm) & Male & Female & $\begin{array}{c}P \\
\text { value }\end{array}$ \\
\hline Length of the canal & $9.02 \pm 1.23$ & $8.98 \pm 1.57$ & 0.05 \\
\hline $\begin{array}{c}\text { Distance from canal } \\
\text { to buccal cortical } \\
\text { plate }\end{array}$ & $4.72 \pm 1.56$ & $4.20 \pm 1.62$ & 0.01 \\
\hline
\end{tabular}

There are many unnamed accessory foramina present in the mandible, especially on the lingual side. They are very variable in their distribution and may be of significance in relation to the effectiveness of local anaesthetic solutions administered for dental procedures. The lingual foramen is situated in the midline, level with or superior to the genial tubercles. McDonnell et al4 found a median lingual foramen in $88.9 \%$ in 126 specimens.

Many anatomical landmarks are present in the anterior mandible,which include the canals and the foramens. The anterior mandibular region between the mental foramens is considered to be safe and has a low risk with regard to causing damage to the vital structures. ${ }^{5}$ The present study was conducted to assess the position of lingual foramen using CBCT.

We found that length of the canal was $9.02 \pm 1.23 \mathrm{~mm}$ in males and $8.98 \pm 1.57 \mathrm{~mm}$ in females. Distance from canal to buccal cortical plate found to be $4.72 \pm 1.56 \mathrm{~mm}$ in males and $4.20 \pm 1.62 \mathrm{~mm}$ in females. Distance from canal to lingual cortical plate was $8.72 \pm 0.72 \mathrm{~mm}$ in group I and $8.26 \pm 1.04 \mathrm{~mm}$ in females. Distance from canal to inferior border was $8.74 \pm 2.41 \mathrm{~mm}$ 


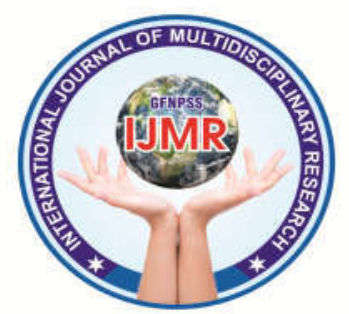

in males and $7.76 \pm 2.32 \mathrm{~mm}$ in females. Distance from canal to alveolus found to be $11.68 \pm 3.36 \mathrm{~mm}$ in males and was $12.25 \pm 3.10 \mathrm{~mm}$ in females. Yildirim et $\mathrm{al}^{6}$ in their CT study assessed the location of lingual foramen and founds that $75.6 \%$ of the canals had diameter less than $1 \mathrm{~mm}$. In present study we observed that diameter of the canal,length of the canal, distance from canal to buccal cortical plate, lingual cortical plate and to inferior border of mandible was more in dentate patients as compared to edentulous patients. Similarly, the angle of canal to Frankfurt horizontal plane was $26.12 \pm 21.4$ degree in group I and $29.14 \pm 22.08$ degree in group II.

A cone beam computed tomography provides three $\square$ dimensional radiographic imaging with greatly reduced doses of radiation (as compared to traditional $\mathrm{CT}$ ) and is becoming a routine diagnostic tool in implant planning. Cone-beam computed tomography (CBCT) provides all three dimensions and has been proved as diagnostic tool in radiology especially in the success of implant. ${ }^{7}$ It provides high spatial resolution and offers less patient exposure as compared to full mouth radiographs and computer tomography (CT). The main drawback of conventional medical CT is the much higher dose that the patient receives and higher cost of the examination in comparison with panoramic radiographs and CBCT images. ${ }^{8}$

\section{CONCLUSION}

The length of the canal, distance from canal to buccal cortical plate, lingual cortical plate, to inferior border and to alveolus found to be more in males than females.

\section{REFERENCES}

1. Dula K, Buser D, Porcellini B, Berthold H, Schwarz M.Computed tomography/oral implantology (I). Dental CT:A program for the computed tomographic imaging of the jaws: the principles and exposure technic. Schweiz Monatsschr Zahnmed 1994; 104:450-9.

2. Woo BM, Al-Bustani S, Ueeck BA. Floor of mouth hemorrhage and life threatening airway obstruction during immediate implant placement in the anterior mandible. Int $\mathrm{J}$ Oral Maxillofac Surg. 2006; 35:961-964.

3. Dreiseidler T, Mischkowski RA, Neugebauer J, et al. Comparison of cone-beam imaging with orthopantomography and computerized tomography for assessment in 


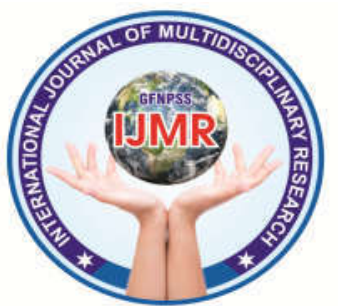

presurgical implant dentistry. Int J Oral

7. Arturo Sanchez-Perez, Paula BoixMaxillofac Implants 2009; 24:216Garcia, and Pía Lopez-Jornet. Cone225.

4. McDonnell D, Reza Nouri M, Todd ME. The mandibular lingual foramen: a consistent arterial foramen in the middle of the mandible. J Anat 1994; 184:363-9.

5. Kim HJ, Choi BY, LeeHY, Chung IH. Morphological study of the mental spine, lingual foramen and nutrient foramen and innominate foramen in Korean mandibles. Korean J Phys Anthropol 1993; 6:129-40. Beam CT Assessment of the Position of the Medial Lingual Foramen for Dental Implant Placement in the Anterior Symphysis. Implant dentistry 2018; 27 (1): 1-6.

8. Kawai T, Asaumi R, Sato I, et al. Classification of the lingual foramina and their bony canals in the median region of the mandible: Cone beam computed tomography observations of dry Japanese mandibles.Oral Radiol. 2007; 23:42-48.

6. Yildirim YD, Güncü GN, GalindoMoreno $\mathrm{P}$, et al.Evaluation of mandibular lingual foramina related to dental implant treatment with computerized tomography:A multicenter clinical study. Implant Dent. 2014; 23:57-63.

9. Makris N, Stamatakis H, Syriopoulos $\mathrm{K}$, et al. Evaluation of the visibility and the course of the mandibular incisive canal and the lingual foramen using cone-beam computed tomography. Clin Oral Implants Res. 201 